\title{
Pancreatic Hepatoid Adenocarcinoma
}

National Cancer Institute

\section{Source}

National Cancer Institute. Pancreatic Hepatoid Adenocarcinoma. NCI Thesaurus. Code C95465.

A rare adenocarcinoma that arises from the pancreas. It is characterized by marked hepatocellular differentiation. 